\title{
Speech delay and autism spectrum behaviors are frequently associated with duplication of the 7q11.23 Williams-Beuren syndrome region
}

Jonathan S. Berg, $M D, P h D^{1}$, ${ }^{*}$, Nicola Brunetti-Pierri, $M D^{1}$, ${ }^{*}$, Sarika U. Peters, PhD ${ }^{1,2}$, Sung-Hae L. Kang, PhD ${ }^{1,3}$, Chin-to Fong, $M D^{4}$, Jessica Salamone, $M S^{4}$, Debra Freedenberg, $M D, P h D^{5}$, Vickie L. Hannig, $M S^{5}$, Lisa Albers Prock, $M D, M P H^{6}$, David T. Miller, $M D, P h D^{7,8}$, Peter Raffalli, $M D^{9}$, David J. Harris, $M D^{7}$, Robert P. Erickson, $M D^{10}$, Christopher Cunniff, $M D^{10}$, Gary D. Clark, $M D^{11}$, Maria A. Blazo, $M D^{1}$, Daniel A. Peiffer, PhD ${ }^{12}$, Kevin L. Gunderson, PhD ${ }^{12}$, Trilochan Sahoo, MD ${ }^{1,3}$, Ankita Patel, $P h D^{1,3}$, James R. Lupski, $M D, P h D^{1,3}$, Arthur L. Beaudet, $M D^{1}$, and Sau Wai Cheung, PhD, $M B A^{1,3}$

\begin{abstract}
Purpose: Williams-Beuren syndrome is among the most well-characterized microdeletion syndromes, caused by recurrent de novo microdeletions at 7q11.23 mediated by nonallelic homologous recombination between low copy repeats flanking this critical region. However, the clinical phenotype associated with reciprocal microduplication of this genomic region is less well described. We investigated the molecular, clinical, neurodevelopmental, and behavioral features of seven patients with dup(7)(q11.23), including two children who inherited the microduplication from one of their parents, to more fully characterize this emerging microduplication syndrome. Methods: Patients were identified by array-based comparative genomic hybridization. Clinical examinations were performed on seven affected probands, and detailed cognitive and behavioral evaluations were carried out on four of the affected probands. Results: Our findings confirm initial reports of speech delay seen in patients with $\operatorname{dup}(7)(q 11.23)$ and further delineate and expand the phenotypic spectrum of this condition to include communication, social interactions, and repetitive interests that are often observed in individuals diagnosed with autism spectrum disorders. Conclusions: Array-based comparative genomic hybridization is a powerful means of detecting genomic imbalances and identifying molecular etiologies in the clinic setting, including genomic disorders such as Williams-Beuren syndrome and $\operatorname{dup}(7)(q 11.23)$. We propose that dup(7)(q11.23) syndrome may be as frequent as Williams-Beuren syndrome and a previously unrecognized cause of language delay and behavioral abnormalities. Indeed, these individuals may first be referred for evaluation of autism, even if they do not ultimately meet diagnostic criteria for an autism spectrum disorder. Genet Med 2007:9(7):427-441.
\end{abstract}

Key Words: 7q11.23, microduplication, language delay, autism spectrum disorder

Williams-Beuren syndrome (WBS) (MIM 194050) is a genomic disorder ${ }^{1}$ affecting $1 / 7,500$ to $1 / 20,000$ livebirths $^{2-4}$ due to sporadic de novo chromosomal microdeletions at 7q11.23 detectable by fluorescence in situ hybridization (FISH). As with many other genomic disorders, the common recurrent $1.55-\mathrm{Mb}$ microdeletion occurs by nonallelic homologous recombination (NAHR) $)^{5}$ between numerous low copy

\footnotetext{
From the ${ }^{I}$ Department of Molecular and Human Genetics, Baylor College of Medicine and Texas Children's Hospital, Houston, Texas; ${ }^{2}$ Leopold Meyer Center for Developmental Pediatrics, Baylor College of Medicine and Texas Children's Hospital, Houston, Texas; ${ }^{3}$ Medical Genetics Laboratories, Baylor College of Medicine Houston, Texas; ${ }^{4}$ Pediatric Genetics, University of Rochester Medical Center, Rochester, New York; ${ }^{5}$ Division of Medical Genetics, Department of Pediatrics, Vanderbilt University Medical Center, Nashville, Tennessee; ${ }^{6}$ Developmental Medicine Center, Children's Hospital Boston; ${ }^{7}$ Division of Genetics, Departments of ${ }^{8}$ Laboratory Medicine and ${ }^{9}$ Neurology, Children's Hospital Boston, Boston, Massachusetts; ${ }^{10}$ Department of Pediatrics, University of Arizona College of Medicine, Tucson, Arizona; ${ }^{11}$ Department of Pediatrics, Section of Pediatric Neurology and Developmental Neuroscience, Baylor College of Medicine and Texas Children's Hospital, Houston, Texas; ${ }^{12}$ Illumina, Inc., San Diego, California.
}

repeats (LCRs) ${ }^{6}$ flanking the commonly deleted region. ${ }^{7-9}$ Inversion of the same segment has been found in $27 \%$ of affected individuals with an atypical WBS phenotype and in 33\% of transmitting parents, suggesting that the presence of this structural variant in the population may be associated with WBS or may predispose to genomic rearrangements. ${ }^{10}$

The WBS phenotype has been extensively studied, and typical individuals have a distinctive facial phenotype, infantile

\footnotetext{
*These authors contributed equally.

Disclosure: The Department of Molecular and Human Genetics at Baylor College of Medicine derives revenue from the chromosomal microarray analysis offered in the clinical cytogenetics laboratory. Illumina and Infinium are registered trademarks of Illumina, Inc.

Sau Wai Cheung, PhD, MBA, Kleberg Cytogenetics Laboratory, Baylor College of Medicine, One Baylor Plaza, NAB 2015, Houston, TX 77030; E-mail: scheung@bcm.edu

Submitted for publication December 6, 2006.

Accepted for publication April 11, 2007.

DOI: 10.1097/GIM.0b013e3180986192
} 
hypercalcemia, growth retardation, cardiovascular anomalies such as supravalvular aortic stenosis (SVAS), connective tissue abnormalities, and a unique cognitive and personality profile. ${ }^{11,12}$ The cognitive profile generally consists of mild to moderate mental retardation with severe disturbance of visuospatial skills but relative sparing of language. From a behavioral standpoint, a striking feature of individuals with WBS is their high sociability and empathy for others, leading them to engage in social interaction even with strangers. ${ }^{13}$

The typical WBS microdeletion is estimated to encompass 25 to 30 genes, ${ }^{12,14-16}$ and haploinsufficiency for several of these genes has been reported to account for parts of the overall phenotype, suggesting that more than one of the genes are sensitive to gene dose or copy number variation. Haploinsufficiency for elastin $(E L N)$, for example, is responsible for SVAS. ${ }^{17}$ Additional genes such as LIMK1, CYLN2, and GTF2IRD1 have also been linked to the cognitive and craniofacial pathology ${ }^{18-21}$ However, the contribution of a subset of the genes located within the deleted region still needs to be elucidated, and so far, there have been no specific genes associated with the unusual language pattern and unique personality profile. The recent finding of altered expression levels of genes with normal copy-number adjacent to the deleted region in WBS patients ${ }^{22}$ adds further complexity to the interpretation of genotype-phenotype correlations in WBS.

Reciprocal duplications have been defined for several deletion disorders mediated by NAHR between LCRs, such as Smith-Magenis syndrome (SMS) involving the $17 \mathrm{p} 11.2$ region $^{23,24}$ and DiGeorge/velocardiofacial syndrome (VCFS) involving the 22q11.2 region. ${ }^{25}$ Given the presence of numerous LCRs and the frequency of microdeletions in the WBS region, it was suspected that reciprocal microduplication of the region should also occur. This prediction was recently verified with the publication of a small number case reports describing individuals with microduplication of the WBS critical region. ${ }^{26-28}$ In the two children for whom detailed clinical information was reported, ${ }^{26,28}$ speech delay was a significant finding; however, the complete phenotypic spectrum associated with microduplications of this region has yet to be elucidated. We report the molecular characterization of nine individuals with $\operatorname{dup}(7)(q 11.23)$ and the clinical, neurodevelopmental, and behavioral features of the seven probands, who presented with varying degrees of developmental delay, prominent language delay, and relative sparing of visuospatial reasoning. A novel feature observed in our patients is the presence of functionally impairing anxiety, decreased social interactions, and repetitive interests similar to children with autism spectrum disorders (ASDs), indicating that the initial clinical presentation of patients with $\operatorname{dup}(7)$ (q11.23) could be an evaluation for autism.

\section{SUBJECTS AND METHODS}

Samples from the patients and their family members underwent clinical diagnostic testing with array-based comparative genomic hybridization (array-CGH) and interphase FISH as detailed below. All patients were examined for dysmorphic features by at least one of the authors during the course of their evaluation. Developmental assessments were carried out by developmental history or standardized testing as detailed below. Behavioral assessments were performed by behavioral history, parental questionnaires, and standardized testing as detailed below. Photographs were obtained and additional research testing was performed after acquiring informed consent approved by the Institutional Review Board for Human Subject Research at Baylor College of Medicine and appropriate institutions.

\section{High-resolution human genome analysis}

To establish an etiology for developmental and language delay and behavioral abnormalities in the patients described below, DNA samples were examined by chromosomal microarray analysis (CMA), ${ }^{29}$ a clinical array-CGH test that permits simultaneous evaluation of copy number variation at large numbers of chromosomal loci (http://www.bcm.edu/cma/assets/ abnormalities.pdf). The version 5 CMA used to test these patients contained 853 FISH-verified human genomic BAC/PAC clones spanning genomic regions implicated in 75 known genetic disorder ${ }^{30}$ as well as all clinically relevant pericentromeric and subtelomeric regions, including nine clones within the WBS region and three clones flanking the WBS LCRs for a total of 12 clones spanning $4.1 \mathrm{Mb}$ of genomic sequence on chromosome 7q11.23. During the course of manuscript preparation, the clinical CMA was transitioned to version 6 , which contains increased backbone clone coverage but has eight clones within the WBS critical region due to removal of a redundant clone. For each patient sample, two parallel experiments were performed with reversal of the dye labels. The quantitated data were normalized and the dye-reversed data were combined to determine fold-change for each clone. All analyses were performed on $\log _{2}$ ratios using code for the normalization and inference that has been implemented at Baylor College of Medicine. ${ }^{29}$

\section{FISH analysis}

Phytohemagglutinin-stimulated peripheral blood lymphoblasts from the patients and their parents were used for interphase FISH. Genomic duplication was visualized by two-color FISH revealing three hybridization signals for the experimental probe and two signals for the control probe. At least 50 interphase nuclei were examined. ${ }^{31}$

\section{Microduplication mapping by oligonucleotide array}

Further analysis of the duplication found in Patient 4 was performed using the HumanHap300 BeadChip from Illumina, Inc. (San Diego, CA), which enables whole-genome genotyping of more than 317,000 oligonucleotide single nucleotide polymorphism (SNP) markers derived from the International HapMap Project (www.hapmap.org). The median spacing between SNPs is $5 \mathrm{~kb}$, providing an effective resolution of $50 \mathrm{~kb}$ using a 10-SNP moving average along the genome. The single base extension Infinium II Assay (Illumina, Inc.) was used for genotyping according to the manufacturer's instructions. In brief, $750 \mathrm{ng}$ of genomic DNA was amplified by whole-genome amplification and fragmented to 500 bp by enzymatic diges- 
tion. Purified DNA was hybridized to the HumanHap300 BeadChip overnight at $48^{\circ} \mathrm{C}$, followed by washing, primer extension, and staining on a Tecan (Zurich, Switzerland) Genesis/ Evo robot using a GenePaint ${ }^{\mathrm{TM}}$ slide processing system. The BeadChips were then washed with low salt wash buffer, coated with a protective agent, and imaged on Illumina's BeadArray Reader, a two-color $(543 \mathrm{~nm} / 643 \mathrm{~nm})$ confocal fluorescent scanner with $0.84-\mu \mathrm{m}$ pixel resolution.

Genotyping data consisted of two-channel intensity data corresponding to the two alleles. Data were normalized using a proprietary algorithm and genotype clusters were created with GenTraining software by clustering on 120 normal individuals. Allelic intensities were transformed to allele frequency (AF; allelic composition) using linear interpolation of the canonical clusters. Data were analyzed in a single sample mode, where reference values were derived from canonical genotyping clusters created from clustering on 120 normal reference samples. Genomic plots of the log base $2\left(\mathrm{R}_{\text {subject }} / \mathrm{R}_{\text {reference }}\right)$ (log R ratio) and the AF parameters along the chromosome form the basis for detecting chromosomal aberrations. ${ }^{32}$

\section{Formal psychological, cognitive, and behavioral testing}

A developmental history was obtained by the clinician for all probands as part of their evaluation. School-based testing records were evaluated for Patient 2, and detailed cognitive testing based on developmental age was completed for Patients 3 and 4 . The Bayley Scales of Infant Development, Third Edition (BSID-III) has appropriate validity and reliability for children whose developmental function is below 42 months of age. $^{33}$ The Vineland Adaptive Behavior Scales (VABS) assess daily living skills, communication, socialization, and motor skills in a standardized fashion. ${ }^{34}$ The Wechsler Preschool and Primary Scale of Intelligence-Third Edition (WPPSI-III) is an individually administered assessment of a child's cognitive abilities involving a variety of activities including verbal and nonverbal reasoning and visuospatial problem solving. ${ }^{35}$ The Beery Developmental Test of Visual Motor Integration, Fifth Edition (VMI) is a standardized measure for children 3 years and older that integrates visual perception with motor output by means of a copying task. ${ }^{36}$ The Wechsler Intelligence Scale for Children-Third Edition (WISC-III) is a conventionally used measure of overall cognitive abilities. ${ }^{37}$ The Kaufman Assessment Battery for Children (K-ABC) includes a nonverbal reasoning subscale. ${ }^{38}$

A behavioral history was obtained by the clinician for all subjects as part of their evaluation. The parents of Patients 1 to 4 provided uniform behavioral information by completing the Aberrant Behavior Checklist-Community Version (ABC$\mathrm{CV}$ ). This form assesses a range of maladaptive behaviors and is normalized against children, adolescents, and adults with mild to profound mental retardation. ${ }^{39}$ The community version of the scale is designed for use with children who are not residing in institutional settings. The rating scale consists of five factors (irritability, lethargy/withdrawal, stereotypy, hyperactivity/noncompliance, and inappropriate speech). Further standardized behavioral testing was performed on $\mathrm{Pa}$ - tients 1 to 4 using the Autism Diagnostic Observation Schedule-Generic (ADOS-G), a semistructured, standardized assessment of communication, social interaction, and play that has been validated to distinguish between cognitive/language delay and ASD. ${ }^{40}$ The ADOS-G may also identify children as having elevated scores (more consistent with ASDs) because of expressive language difficulties paired with anxiety affecting the child's performance on the measure.

\section{RESULTS}

\section{Case reports}

Seven probands with dup(7)(q11.23) were identified by CMA performed in the Kleberg Cytogenetics Laboratory (Fig. 1). The clinical presentations are detailed below and representative photographs of four individuals are shown in Figure 2. Clinical, $\operatorname{cog}$ nitive, and behavioral features are summarized in Tables 1 to 3 .

\section{Case 1}

This $3 \frac{1}{1} 2$-year-old white boy was evaluated for global developmental delay. He had cleft lip and palate, which were repaired surgically. In addition, he exhibited right-sided torticollis that resolved at 4 months of age with physical therapy. At 18 months, his language was assessed at the 8-month level. At 21 months, he was diagnosed with a seizure disorder and started on carbamazepine. Developmental milestones indicated continued global developmental delay, despite receiving physical therapy since birth. In addition, he was diagnosed with attention-deficit/hyperactivity disorder (ADHD) and was noted to exhibit behaviors consistent with ASDs such as lacking emotional responsiveness, repetitive hand/body movements, "staring" into space, excessive activity, disrupting group activities, and unresponsiveness to structured activities. Family history revealed three previous miscarriages and two older brothers with ADHD. At 30 months of age, the physical examination revealed frontal prominence, midface hypoplasia, mild helical overfolding, a short philtrum, and generalized hypotonia (Fig. 2, A and Table 1). Brain magnetic resonance imaging (MRI) showed mild cerebral atrophy.

\section{Case 2}

This $113 / 4$-year-old white boy was evaluated for global developmental delay and behavioral problems. His medical history included vesicoureteral reflux (VUR) that required surgical correction and ADHD, which is treated with methylphenidate. His mother reported that he had episodes of facial flushing associated with fevers of unknown etiology. His gross motor and speech milestones were significantly delayed, and his behavioral characteristics included aggressive tendencies (pinching and hitting) and self-injurious behavior such as arm twisting and pinching, hand and arm biting and face scratching. Of recent concern to the mother were increasing temper tantrums and biting. The family history was significant for ADHD in the patient's brother. On examination, he was noted to have mild malar hypoplasia, low-set ears, and mildly decreased muscle tone (Fig. 2, B and Table 1). 


\section{Berg et al.}
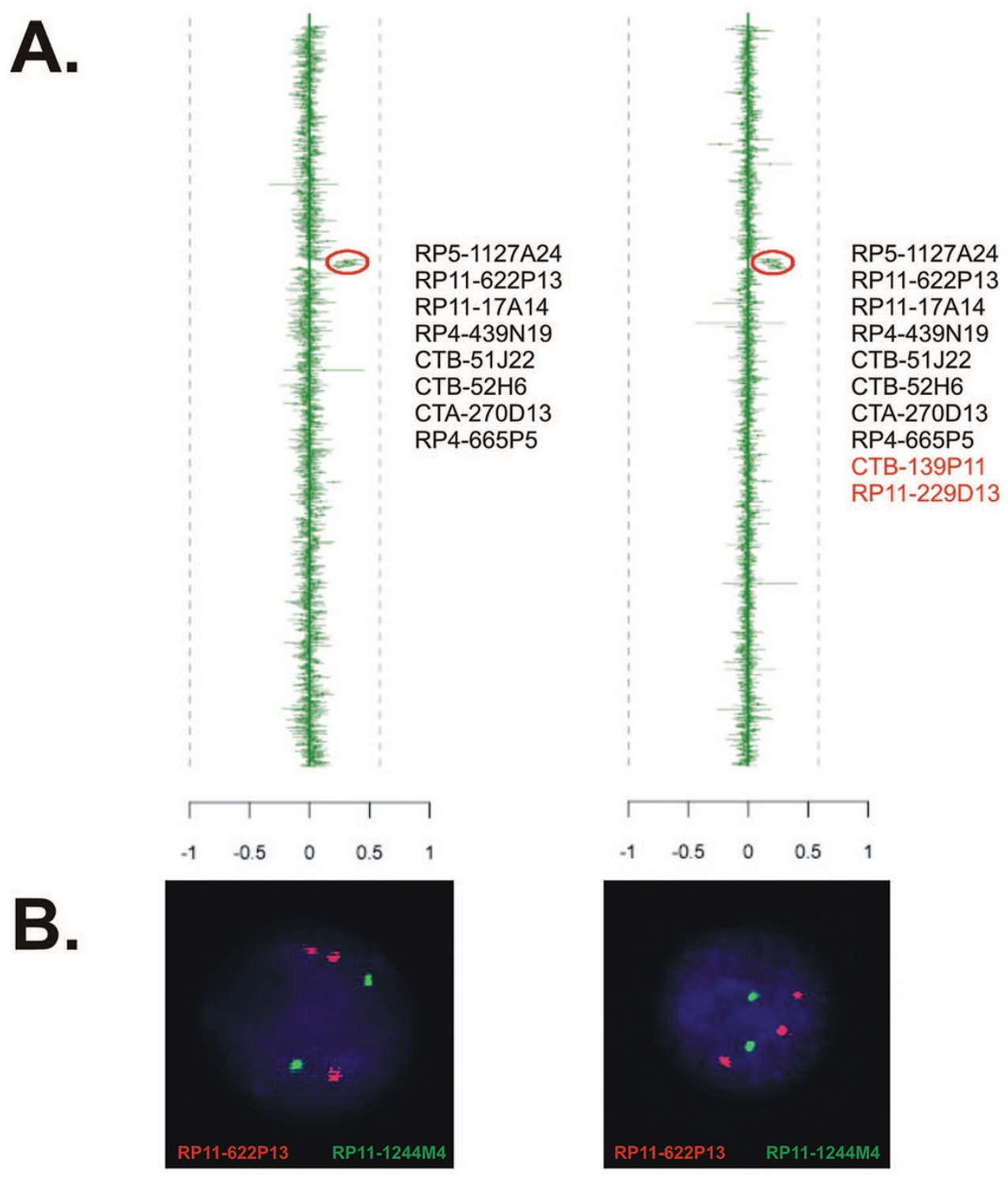

\section{Case $1,2,3,5,5^{m}, 6,6^{m}, 7 \quad$ Case 4}

Fig. 1. Identification of dup(7)(q11.23) by CMA. Clinical array-CGH testing identified microduplication of chromosome 7q11.23 in seven probands and two transmitting parents. (A) Representative CMA output. Clinical samples referred for CMA testing undergo two parallel experiments with reversal of the dye labels. The quantitated data are normalized, and the dye-reversed data are combined to determine fold-change for each clone. Combined data for each clone are represented in green along a vertical line that indicates the relative position of the clone from chromosome 1 (top) to chromosome $\mathrm{X}$ and $\mathrm{Y}$ (bottom). Loss of copy number is indicated by deviation to the left of center, whereas gain of copy number is indicated by deviation to the right of center. CMA revealed a gain in copy number for clones within the WBS critical region, indicated by a red circle, in samples from Patients $1,2,3,5,5^{\mathrm{m}}, 6,6^{\mathrm{m}}$, and 7 (left). CMA revealed a gain in copy number for clones within the WBS critical region and two clones telomeric to the LCR, in the sample from Patient 4 (right). (B) Representative interphase FISH analysis. The red signal is from the test probe and the green signal is from a control chromosome 7 probe. The presence of three red signals compared with two green signals indicates a duplication of the region detected by the test probe. The names of each probe are shown in red and green, respectively.

\section{Case 3}

This $4 \frac{1}{2}$-year-old white girl was previously diagnosed with pervasive developmental disorder nearly 2 years earlier based on delayed speech, reduced eye contact, and repetitive behaviors. Her medical history was significant for hypotonia, frequent otitis media, and constipation. Gross and fine motor milestones were slightly delayed during infancy but were improved at the time of evaluation, albeit with some difficulty with motor planning. She displayed significant speech delay but used $>300$ signs and gestures to communicate with family members. She had a history of significant sleep disturbance including outbursts of screaming that responded to risperidone therapy (now discontinued with no recurrence of sleep disturbance). She had a strong history of sensory issues, anxiety, and withdrawal in crowded situations. Family history was significant for language delay in the father and two of the paternal grandfather's brothers, and a diagnosis of ADHD in the paternal grandfather's sister. Physical examination revealed mild dysmorphic 

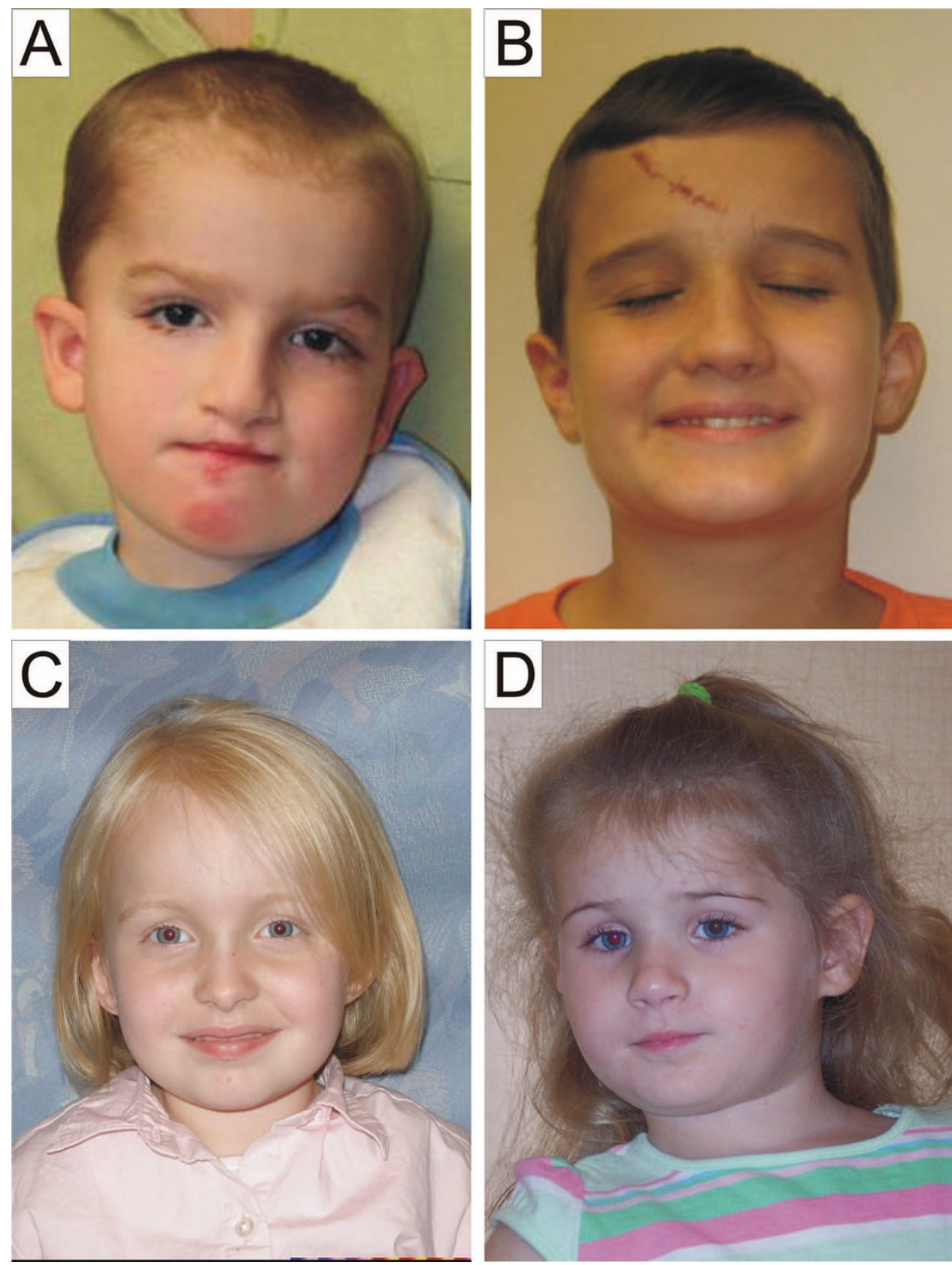

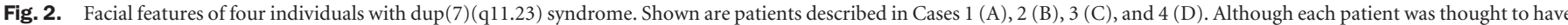
mild dysmorphisms, there is not a strongly recognizable pattern of facial features that could permit identification of these patients by clinical examination.

features including a slightly elongated columella, short philtrum, thin lips, and other minor anomalies including mild cubitus valgus, fifth finger clinodactyly, joint laxity, and slight hypotonia (Fig. 2, C and Table 1). At the time of referral for diagnostic clarification, she was found to have severe communication disorder, oromotor apraxia, and significant anxiety affecting her expressive language output. Over the course of the following 6 months, however, her speech improved dramatically.

\section{Case 4}

This 3-year-old white girl was evaluated for speech delay and possible ASD. Her language milestones were significantly de- layed, and although she was laughing out loud, she had not developed any words that were easily intelligible. However, she used several infant signs, had fairly appropriate receptive language, could point to body parts, identify animals, and follow 2 -step commands. By 18 months of age, there were concerns for mild autism-spectrum features such as difficulty with eye gaze, excessive lining up of toys, and significant separation and stranger anxiety. The family history was unremarkable. Physical examination revealed normal growth parameters and mild facial dysmorphic features (Fig. 2, D and Table 1). The brain MRI showed mild prominence of the lateral and third ventricles, but no dilatation or hydrocephalus, suggesting a mild re- 
Table 1

Physical characteristics of individuals with $\operatorname{dup}(7)(\mathrm{q} 11.23)$ syndrome

\begin{tabular}{|c|c|c|c|c|c|c|c|c|c|c|}
\hline & Pt 1 & Pt 2 & Pt 3 & Pt 4 & Pt 5 & Pt 6 & Pt 7 & $\begin{array}{l}\text { Somerville } \\
\text { et al. }^{26}\end{array}$ & Kriek et al. ${ }^{27}$ & $\begin{array}{l}\text { Torniero } \\
\text { et al. } .^{28}\end{array}$ \\
\hline \multicolumn{11}{|l|}{ Growth } \\
\hline $\begin{array}{l}\text { Age at } \\
\text { examination }\end{array}$ & $31 / 2 y$ & $113 / 4 \mathrm{y}$ & $4^{1} / 2 y$ & $3 y$ & $7 y$ & $6 y$ & $19 y$ & $8 \mathrm{y}$ & $1 \mathrm{y}$ & $12 y$ \\
\hline Height (\%ile) & 90th & 5th-10th & 50th-75th & 80th & 50th & 10th-25th & 25 th & 2nd & n.a. & 25th-50th \\
\hline Weight (\%ile) & 90th & 7th & 50th-75th & 62nd & 90th-97th & 25th & 75th & 5 th & n.a. & 75th-90th \\
\hline FOC (\%ile) & n.a. & 50th-75th & 75th & 72nd & $>95$ th & 90th & n.a. & 30th & n.a. & $>95$ th \\
\hline $\begin{array}{l}\text { Birth length } \\
\quad \text { (\%ile) }\end{array}$ & n.a. & 75 th & n.a. & 90th & n.a. & n.a. & n.a. & $<5$ th & n.a. & 10th \\
\hline $\begin{array}{l}\text { Birth weight } \\
\text { (\%ile) }\end{array}$ & 50 th & 25th & 50 th & 25th-50th & 95th & n.a. & 10th & $<5$ th & n.a. & 75th \\
\hline Birth FOC (\%ile) & n.a. & n.a. & n.a. & n.a. & n.a. & n.a. & n.a. & 10th & n.a. & 50th \\
\hline \multicolumn{11}{|l|}{ Facial features } \\
\hline $\begin{array}{l}\text { Prominent } \\
\text { forehead }\end{array}$ & + & + & + & + & - & - & - & + & n.a. & - \\
\hline Hypertelorism & - & - & - & - & + & - & - & - & n.a. & - \\
\hline High/broad nose & + & + & - & + & - & - & + & + & n.a. & - \\
\hline $\begin{array}{l}\text { Anteverted nares/ } \\
\text { long columella }\end{array}$ & + & - & + & - & - & - & - & - & n.a. & - \\
\hline Low/rotated ears & + & + & - & - & - & - & - & + & n.a. & + \\
\hline Abnormal helices & + & - & - & + & - & - & + & - & n.a. & - \\
\hline Malar hypoplasia & + & + & - & - & - & - & - & - & n.a. & + \\
\hline Short philtrum & + & + & + & - & - & - & - & + & n.a. & + \\
\hline Thin lips & + & + & + & + & - & - & - & + & n.a. & + \\
\hline Small jaw & - & - & - & - & - & - & - & + & n.a. & + \\
\hline $\begin{array}{l}\text { Dental crowding/ } \\
\text { malocclusion }\end{array}$ & - & - & - & - & - & - & + & + & n.a. & - \\
\hline High palate & - & - & - & - & - & - & + & + & n.a. & - \\
\hline \multirow[t]{4}{*}{ Other } & $\mathrm{CL} / \mathrm{CP}$ & VUR & Pes planus & - & $\begin{array}{l}\text { Shawl } \\
\text { scrotum }\end{array}$ & $\begin{array}{l}\text { Café-au-lait } \\
\text { macules }\end{array}$ & $\begin{array}{l}\text { Submucous } \\
\text { CP }\end{array}$ & - & Craniosynostosis & $\begin{array}{c}\text { Café-au-lait } \\
\text { macules }\end{array}$ \\
\hline & Hypotonia & Hypotonia & Hypotonia & & Neutropenia & Thin fingers & $\begin{array}{l}\text { Tapered } \\
\text { fingers }\end{array}$ & & & $\begin{array}{l}\text { Cubitus } \\
\text { valgus }\end{array}$ \\
\hline & Torticollis & & Constipation & & Astigmatism & & GER & & & Clubfoot \\
\hline & $\begin{array}{l}\text { Seizure } \\
\quad \text { disorder }\end{array}$ & & & & & & $\begin{array}{l}\text { Seizure } \\
\quad \text { disorder }\end{array}$ & & & $\begin{array}{l}\text { Seizure } \\
\quad \text { disorder }\end{array}$ \\
\hline
\end{tabular}

n.a., data not available; FOC, frontooccipital circumference; CL/CP, cleft lip and cleft palate; VUR, vesicoureteral reflux; CP, cleft palate; GER, gastroesophageal reflux.

duction in overall volume in the absence of focal morphologic brain abnormalities, and no evidence of cortical dysplasia.

\section{Case 5}

This 7-year-old white boy was followed for speech delay and dysmorphic features. He first used clearly understandable words at 3 to 4 years of age, and at age $53 / 4$ years, his speech consisted of single words with a vocabulary of $<100$ words. At 7 years of age, he used sentences and was reportedly doing well in his school program. His gross motor milestones were mildly delayed. There was concern for behavioral abnormalities including hyperkinetic movement, pulling of his hair, and stereotypical movements such as tensing his body and flapping his hands. He had a history of unexplained neutropenia and hyperopic astigmatism. Physical examination revealed macrocephaly but otherwise normal growth parameters, ocular hypertelorism, and shawl scrotum. The brain MRI showed nonspecific prominence of the ventricles and subarachnoid spaces and nonspecific white matter T2 signal abnormality, possibly representing gliosis, but no evidence of cortical malformation. 
Table 2

Cognitive characteristics of individuals with $\operatorname{dup}(7)(\mathrm{q} 11.23)$ syndrome

\begin{tabular}{|c|c|c|c|c|c|c|c|c|c|c|}
\hline & Pt 1 & Pt 2 & Pt 3 & Pt 4 & Pt 5 & Pt 6 & Pt 7 & $\begin{array}{c}\text { Somerville } \\
\text { et al. }{ }^{26}\end{array}$ & $\begin{array}{l}\text { Kriek } \\
\text { et al. }\end{array}$ & $\begin{array}{l}\text { Torniero } \\
\text { et al. }\end{array}$ \\
\hline \multicolumn{11}{|l|}{ Development } \\
\hline Overall MR/DD & Mild & Mild & Mild & Mild & Mild & Moderate & Moderate & Mild & n.a. & Mild \\
\hline Visuospatial & n.a. & Spared & Spared & Spared & n.a. & n.a. & n.a. & Spared & n.a. & Spared \\
\hline Speech delay & ++ & + & + & ++ & + & ++ & + & ++ & + & ++ \\
\hline Motor delay & + & + & + & - & + & + & + & + & n.a. & - \\
\hline Motor milestones & Delayed & Delayed & Delayed & Normal & Delayed & Delayed & Delayed & Delayed & n.a. & Normal \\
\hline Sat & $15 \mathrm{mo}$ & $12 \mathrm{mo}$ & n.a. & $6 \mathrm{mo}$ & $8 \mathrm{mo}$ & n.a. & $8 \mathrm{mo}$ & $12 \mathrm{mo}$ & n.a. & n.a. \\
\hline Walked & $18 \mathrm{mo}$ & $18 \mathrm{mo}$ & $21 \mathrm{mo}$ & $12 \mathrm{mo}$ & $14.5 \mathrm{mo}$ & $24 \mathrm{mo}$ & $18 \mathrm{mo}$ & $24 \mathrm{mo}$ & n.a. & n.a. \\
\hline \multirow[t]{2}{*}{ Audiology } & PE tubes & Normal & Normal & PE tubes & Normal & n.a. & n.a. & Normal & n.a. & Normal \\
\hline & Freq. OM & & Freq. OM & Freq. OM & & & & & & \\
\hline Cognitive tests & n.a. & & & & n.a. & n.a. & n.a. & & n.a. & n.a. \\
\hline Verbal & & $60^{a}$ & $81^{c}$ & $53^{e}$ & & & & $65^{f}$ & & \\
\hline Nonverbal & & $62^{a} / 87^{b}$ & $104^{c}$ & $80^{e}$ & & & & $65^{f}$ & & \\
\hline Receptive language & & n.a. & $120^{d}$ & $48^{e}$ & & & & $82^{g}$ & & \\
\hline Expressive language & & n.a. & $85^{d}$ & $30^{e}$ & & & & $40^{h}$ & & \\
\hline Motor & & n.a. & $83^{c}$ & $61^{e}$ & & & & n.a. & & \\
\hline
\end{tabular}

n.a., data not available; PE tubes, pressure equalization tubes; MR/DD, mental retardation or developmental disability; Freq. OM, frequent otitis media.

${ }^{a}$ Determined using the WISC-III.

${ }^{b}$ Determined using the nonverbal composite score from the K-ABC.

${ }^{c}$ Determined using the WPPSI-3.

${ }^{d}$ Determined using general language subtest scores (receptive vocabulary and picture naming) from the WPPSI-3, credit given for gestures and signs.

${ }^{e}$ Determined using the BSID-III.

${ }^{f}$ Determined using the Differential Ability Scales.

${ }^{g}$ Determined using the Peabody Picture Vocabulary Test III.

${ }^{h}$ Determined using the Expressive Vocabulary Test.

After the diagnosis of dup(7)(q11.23) was made, the mother of Patient 5 (hereafter referred to as Patient $5^{\mathrm{m}}$ ) underwent testing by interphase FISH and CMA and was found to carry the same microduplication as her son. Although complete clinical information was not available, she works independently and does not have any significant medical concerns.

\section{Case 6}

This 6-year-old Native American boy was evaluated for global developmental delay with delayed motor milestones and severe language delay. He met all his motor milestones late, with independent ambulation beginning after 2 years of age. However, his speech and language skills were more dramatically impaired, and at 6 years of age, he used only single-word utterances. His vocabulary consisted mostly of the names of simple objects and family members. He has always received schooling in a self-contained classroom setting and is currently in a third grade classroom where he can write his name and recognize some letters and numbers. Behaviorally, he exhibits high activity and is described as "difficult." The school requested an evaluation for ADHD, but this has not been completed. On examination, he had a number of scattered, irregular, hyperpigmented lesions and hyperpigmented spots in his inguinal area and axillary area. However, these features were not consistent with those seen in neurofibromatosis type 1 (NF1), and he did not meet diagnostic criteria for NF1. The brain MRI was within normal limits.

After the diagnosis of dup (7)(q11.23) was made, the parents were tested by interphase FISH and CMA. The mother of Patient 6 (hereafter referred to as Patient $6^{\mathrm{m}}$ ) was found to carry the same microduplication as her son. Although complete clinical information was not available, she completed high school in a regular classroom setting, and she does not exhibit any developmental disability.

\section{Case 7}

This 19-year-old white woman was evaluated for longstanding mental retardation, seizure disorder, and a history of a submucous cleft palate. Her medical history also includes significant gastroesophageal reflux for which she was hospitalized at 11 years of age, tonsillectomy and adenoidectomy, and a heart murmur. In addition, she has recently begun to suffer panic attacks. Her first generalized tonic-clonic seizure was at 7 months of age, and she was treated with phenobarbital until 6 years of age, after which she was seizure free. Developmental milestones were globally delayed, but speech was more severely 
Table 3

Behavioral characteristics of individuals with $\operatorname{dup}(7)(\mathrm{q} 11.23)$ syndrome

\begin{tabular}{|c|c|c|c|c|c|c|c|c|}
\hline & Pt 1 & Pt 2 & Pt 3 & Pt 4 & Pt 5 & Pt 6 & Pt 7 & Somerville ${ }^{26}$ \\
\hline \multicolumn{9}{|l|}{ Behavioral history $^{a}$} \\
\hline Anxiety & + & - & + & + & - & - & + & \\
\hline Self-injurious behavior & - & + & - & - & + & - & - & \\
\hline Aggression & + & + & + & - & - & - & - & \\
\hline Attention deficit/hyperactivity & + & + & - & - & - & $+/ ?^{b}$ & - & + \\
\hline Sensory integration & - & - & + & - & - & - & - & \\
\hline Stereotyped movements & - & - & + & + & + & - & - & \\
\hline Repetitive play/behavior & - & + & + & + & - & - & - & \\
\hline $\mathrm{ABC}-\mathrm{CV}^{c}$ & & & & & n.a. & n.a. & n.a. & n.a. \\
\hline Irritability/aggression & + & + & - & - & & & & \\
\hline Lethargy/withdrawal & + & - & + & - & & & & \\
\hline Stereotypy & + & - & - & - & & & & \\
\hline Hyperactivity/noncompliance & + & - & - & - & & & & \\
\hline Repetitive/inappropriate speech & + & + & - & - & & & & \\
\hline ADOS- $\mathrm{G}^{d}$ & & & & & n.a. & n.a. & n.a. & n.a. \\
\hline Communication & 3 & 1 & 1 & 3 & & & & \\
\hline Social interaction & 1 & 2 & 1 & 4 & & & & \\
\hline Communication + social interaction ${ }^{e}$ & 4 & 3 & 2 & 7 & & & & \\
\hline Imaginative play & 1 & 3 & 0 & 1 & & & & \\
\hline Stereotyped behaviors & 1 & 0 & 0 & 2 & & & & \\
\hline
\end{tabular}

n.a., data not available; ABC-CV, Aberrant Behavior Checklist-Community Version; ADOS-G, Autism Diagnostic Observation Schedule-Generic.

${ }^{a}$ Presence based on parental report/clinical history.

${ }^{b}$ No formal evaluation.

${ }^{c}$ For each subscale, + indicates a score greater than the mean.

${ }^{d}$ Numbers indicate score of ADOS-G subscales.

${ }^{e}$ Cutoff for autism spectrum disorders $=4$, cutoff for autism $=6$.

affected, with her first words at 2 years of age. She suffered from a speech impediment due to the submucous cleft palate, which was identified at 3 years of age on evaluation for speech delay. She has undergone two corrective surgeries for the submucous cleft and received speech therapy throughout childhood. Although she has not yet undergone formal assessment, her mental function is reportedly that of a 6 to 8 year old. On examination, she was noted to have small and simple ears, a somewhat tubular nose, a high-arched palate and dental crowding, and a grade II/VI cardiac murmur. Her speech was dysarthric and had a nasal tone. Her previous evaluation at 8 years of age included a conventional karyotype and FISH for VCFS, both of which were normal. An echocardiogram revealed no structural heart defects.

\section{Genomic analysis with array-CGH reveals 7q11.23 microduplication}

Gain of copy number in the WBS region on chromosome 7q11.23 was revealed by CMA in all eight cases (Fig. 1, A). In Patients 1 to $3,5,5^{\mathrm{m}}, 6,6^{\mathrm{m}}$, and 7 , increased copy number was found for all the clones that map within the region commonly deleted in WBS (RP5-1127A24, RP11-622P13, RP11-17A14, RP4-439N19, CTB-51J22, CTB-52H6, CTA-270D13, and RP4-665P5). Although the clinical CMA does not include clones mapping within the LCRs, clones immediately adjacent to these regions (centromeric RP11-815K3 and telomeric CTB-139P11 and RP11-229D13) were normal in each of these individuals. Genomic duplication was independently confirmed by interphase FISH using clones RP5-1177A1, RP11$622 \mathrm{P} 13$, and/or RP4-665P5 to quantitate copy number. In all cases, the hybridization signals obtained were consistent with duplications (Fig. 1, B).

In Patient 4 , the gain in copy number extended distally beyond the telomeric LCR and included adjacent clones CTB139P11 and RP11-229D13 (Fig. 1, A). The duplication was confirmed by FISH using a clone within the common region, RP11-622P13 (Fig. 1, B), and clone RP11-229D13 (data not shown). Because the clinical CMA is targeted toward known disease-specific genomic regions, there is a lower density of clones outside the WBS region. The nearest clone on the CMA that had normal copy number was $36.7 \mathrm{Mb}$ distal to the duplicated clones, yielding a minimal duplication size of $3.5 \mathrm{Mb}$ and 


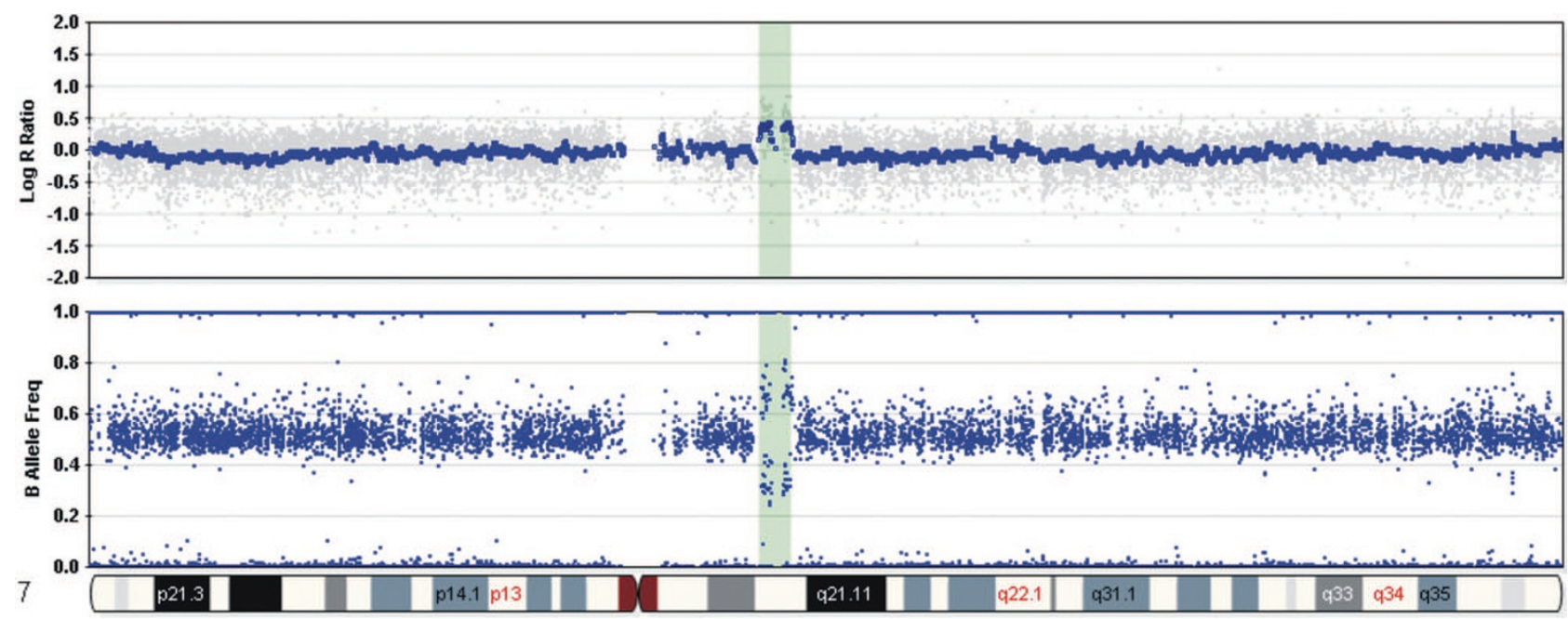

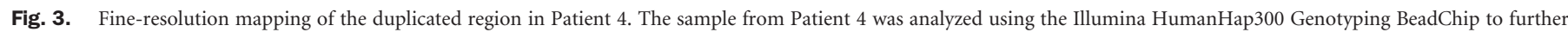

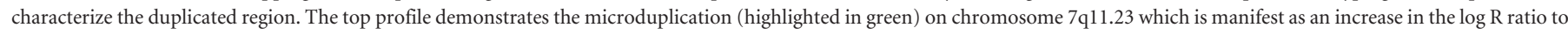

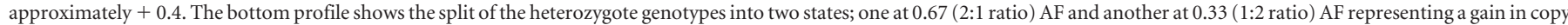

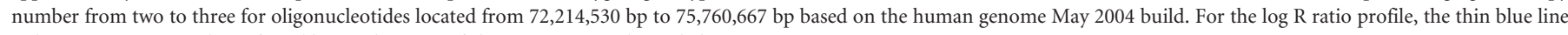
indicates a moving median of $200 \mathrm{~kb}$. An ideogram of chromosome 7 is shown below.

a maximal duplication size of $40.2 \mathrm{Mb}$. We therefore performed additional fine-resolution mapping of the duplicated region with the HumanHap 300 oligonucleotide SNP genotyping array (Illumina, Inc.) and found that the duplication extended from SNPs located at approximately 72,214,530 bp to 75,760,667 bp (based on the Human Genome May 2004 assembly), yielding an approximate duplication size of $3.55 \mathrm{Mb}$ (Fig. 3), which includes several additional genes including HSPB1, YWHAG, SRCRB4D, ZP3, and DTX2. This region is telomeric to the well-characterized WBS LCRs, but there is additional low-copy repeat structure in this area that could potentially mediate NAHR (UCSC Genome Browser ${ }^{41}$ segmental duplication track $^{42}$ [accessed October 2006]). Despite the atypical duplication, this patient does not seem to have additional or more severe features compared with the others (see below).

Samples from both parents were obtained for Patients 1, 3, 4, and 6, whereas only maternal samples were available for $\mathrm{Pa}$ tients 2 and 5. Parental samples for Patient 7 were not available. None of the tested family members of Patients 1 to 4 harbor the duplication. The samples were subjected to interphase FISH using a control probe outside the duplicated region and a test probe within the duplicated region. Although interphase FISH was generally reliable for detecting normal copy number in these individuals, there was an instance in which a paternal sample was initially scored as carrying a duplication that on further analysis with CMA was determined to have normal copy number. The reason for this discrepancy is unknown and will require further molecular characterization. Interphase FISH analyses for Patients $5^{\mathrm{m}}$ and $6^{\mathrm{m}}$ were consistent with duplication, and were confirmed by CMA to involve the same clones within the WBS critical region.

These data indicate that in most cases, a common genomic interval is duplicated in these individuals (Fig. 4). Given the absence of gain in copy number for clones flanking the WBS LCRs, our findings are consistent with the rearrangements representing the $1.55 \mathrm{Mb}$ reciprocal microduplication to the common WBS microdeletion. Four of the seven probands described herein harbor apparently de novo duplications, whereas two individuals inherited duplications from their mothers. The larger duplication seen in Patient 4 may represent an uncommon (or unique) variant as has been seen in some patients with atypical WBS deletions. ${ }^{12}$

\section{Cognitive and behavioral evaluation}

Results of cognitive testing are summarized in Table 2. Patient 2 was tested with the WISC-III and K-ABC as part of his school-based evaluation. His verbal reasoning skills were within the range of mild deficits, whereas his nonverbal reasoning skills and overall adaptive behavior were significantly stronger and fell within the low average range. Patient 3 underwent formal cognitive evaluation using the WPPSI-III and VMI. Her verbal abilities were within the low average range, and she demonstrated mild graphomotor delays, but her nonverbal cognitive abilities were significantly higher and fell within the average range. Before her evaluation at $4 \frac{1}{2}$ years, she communicated primarily via signs and gestures and had signs of oromotor dyspraxia. The only verbal language she used during the evaluation consisted of "ha-ha" and a pig noise. However, after treatment of her anxiety symptoms with fluoxetine, she had an increase in her expressive language skills and exhibited a dramatic improvement over the subsequent 6 months. Patient 4 underwent testing with the BSID-III and demonstrated significant weaknesses in language skills, with receptive language skills at the 19-month level and expressive language skills at the 12-month level at a chronological age of 36 months. In contrast, her measures of visuospatial and nonverbal skills fell within the low average range. Her overall motor skills were 

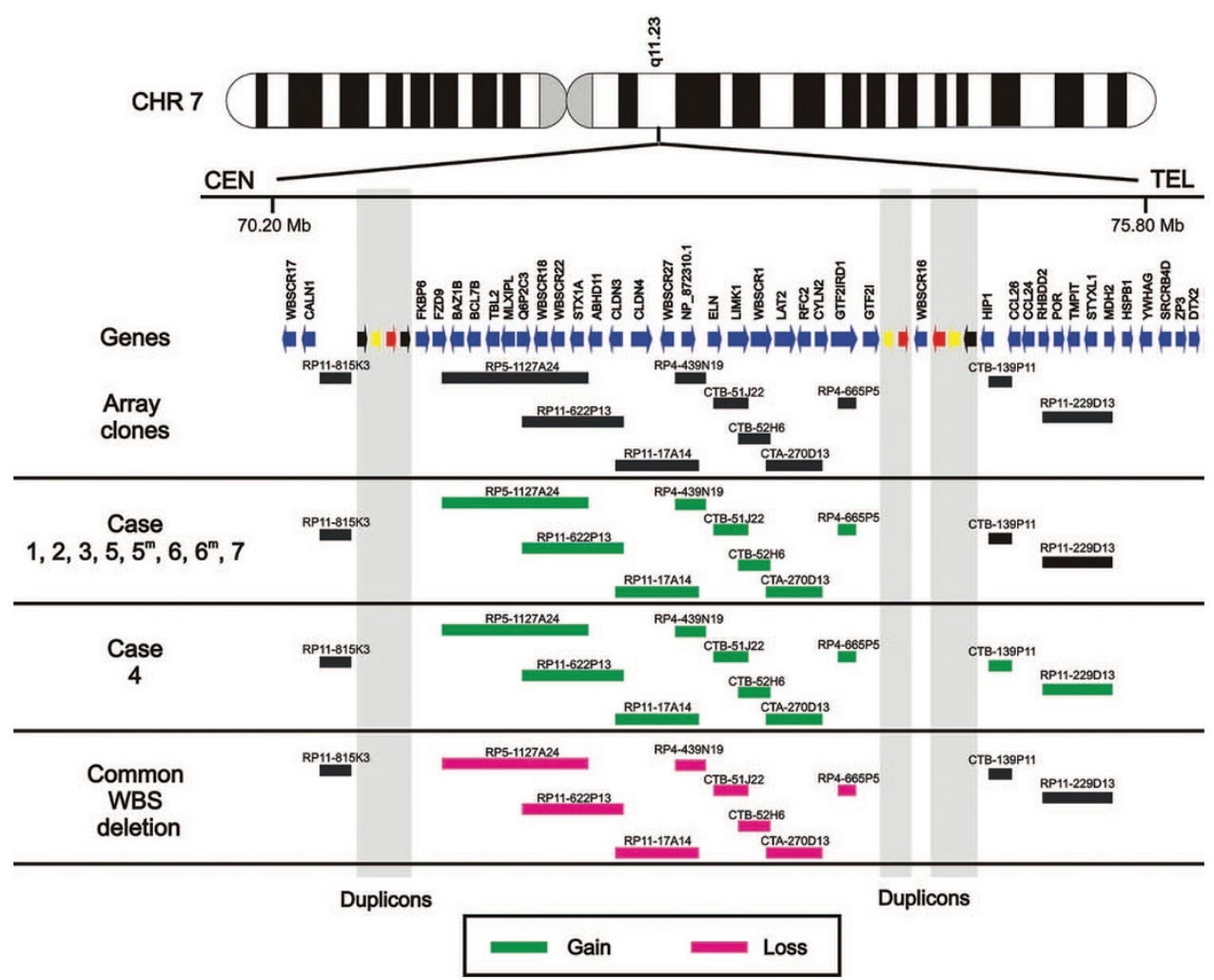

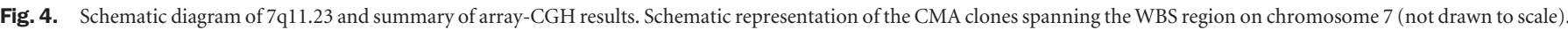

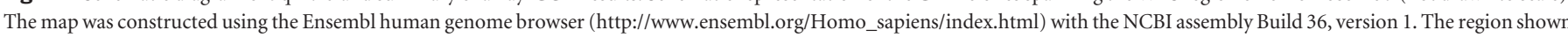

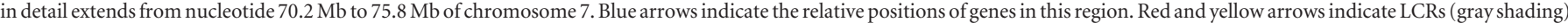

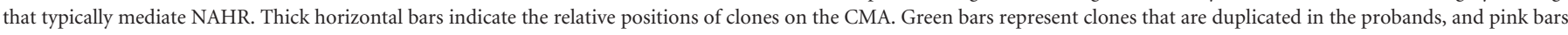
represent clones that are commonly deleted in WBS patients.

slightly lower compared with her cognitive abilities, with fine motor skills at the 23-month level and gross motor skills at the 17-month level. Her overall adaptive behavior (as assessed by the VABS) showed mild deficits in the range of the low adaptive level, particularly in communication and motor skills. Her parents reported that her self-help skills and her socialization skills fell within the moderately low range.

Results of behavioral testing are summarized in Table 3. The aberrant behavior checklists completed by the parents provided a comparison between Patients 1 to 4. Patient 1 exhibited high scores for maladaptive behaviors on all five subscales. He had several behaviors seen in children with developmental delay and ASDs including repetitive hand movements, sensory integration issues, disruptiveness, and a lack of emotional responsiveness. Patient 2 exhibited significant elevations for irritability/aggression and repetitive/inappropriate speech. He displayed self-injurious behaviors, aggression, perseveration on certain words or thoughts, repetitive language use, and repetitive play behaviors such as watching the same video repeatedly. Patient 3 exhibited elevations only on the lethargy/withdrawal subscale. She has a history of sensory integration abnormalities (for example, when a human hair falls on her, she screams until the hair is removed), and she avoids eye gaze when she becomes overwhelmed. She has social difficulties in terms of seeking isolation from others and preferring solitary activities, especially when overwhelmed. She has a history of aggressiveness, severe tantrums, difficulty with transitions, fixation on activities of interest, and stereotyped play, all of which have improved over time with intensive behavioral treatment. Patient 4 did not have any increase in scores on the ABC-CV subscales at the time of evaluation.

Patients 1 to 4 were also evaluated with the ADOS-G. Patient 1 underwent psychological testing as part of his initial workup because of concerns that he could have an ASD. His combined communication and social interaction scores met the minimum criteria for an ASD on the ADOS-G, and several concerning behaviors were noted, including oversensitivity to noises, lack of a smile in response to another person smiling, repetitive movements, and repetitive play. His strengths included the use of nonverbal gestures, pointing, and shared enjoyment in interactions. The scores of ADOS-G testing for Patient 2 were clearly below the threshold for a diagnosis of an ASD. He used good eye contact and facial expressions and interacted meaningfully with his mother. He did endorse some special interests but did not seem obsessed with a particular activity or topic. Patient 3 was originally given the diagnosis of pervasive developmental disorder at 3 years of age but showed significant improvement at $4 \frac{1}{2}$ years of age. Her scores on the ADOS-G were also below the cutoff for an ASD despite some of her past behavioral concerns. Patient 4 also had features consistent with 
an ASD at her initial evaluation, including a history of repetitive play (lining up toys), difficulties with eye gaze, and avoiding other children. Her overall scores on the ADOS-G were just above the lowest threshold of the cutoff for an ASD. Autismlike behaviors noted during the examination included her use of other peoples' hands as tools with which to communicate, hand flapping, a limited range of facial expressions, showing objects without coordinated eye gaze, some repetitive play, and some anxiety in response to loud noises. Despite these behaviors, she used a wide range of nonverbal gestures and nearly all her vocalizations were socially directed; she exhibited shared enjoyment in multiple interactions, was not overly focused or repetitive in her play, and exhibited developmentally appropriate play skills.

\section{DISCUSSION}

Segmental aneuploidies are an important determinant of many human diseases. Analysis of the reference sequence shows that $5 \%$ of the human genome is duplicated. ${ }^{43}$ These segmental duplications are thought to have had a key role in human genome evolution ${ }^{5}$ and may be responsible, through NAHR, for many chromosome rearrangements leading to human disease. ${ }^{1,5,44}$ Segmental duplications create genome instability that can lead to genomic rearrangements with consequential dose imbalance or misregulation of gene(s) necessary for normal human development. ${ }^{45}$ Interestingly, the gain or loss of chromosomal fragments may contribute to disease phenotypes by modifying the levels of expression of genes lying in proximity to the breakpoints. ${ }^{22}$

\section{Identification of the dup(7)(q11.23) syndrome}

Given the frequency of patients with de novo microdeletions of the WBS critical region, it is surprising that microduplication of the WBS region was first reported only recently. ${ }^{26-28}$ This is likely due to a convergence of factors. First, the phenotypes seen in patients with microduplications of chromosome $7 \mathrm{q} 11.23$ are quite unlike those seen with the common WBS microdeletion, and FISH examination of metaphase cells is unlikely to detect the microduplication. ${ }^{31}$ Clinicians would be unlikely to order interphase FISH for WBS in patients who were not clinically suspected to have WBS. In fact, the first patient reported to harbor a microduplication of chromosome 7q11.23 was initially evaluated for VCFS by a real-time PCR approach that instead fortuitously revealed duplication of markers within the WBS region. ${ }^{26}$

Second, although the recombination reciprocal of the WBS microdeletion was postulated to occur, ${ }^{1}$ it would have been difficult to predict the phenotype associated with the microduplication based on what was known about the contributions of genes in this region to the WBS phenotype. However, a screen of individuals with a relatively nonspecific phenotype (developmental delay and congenital malformations) using a multiplex amplification approach that simultaneously assayed several genomic regions identified one individual who inherited a microduplication of chromosome $7 \mathrm{q} 11.23$ from his father. ${ }^{27}$
The brief description of the patient indicated that he had craniosynostosis, but did not include any neurodevelopmental or cognitive assessment. Minimal information was available for the father of the subject. In a note added in proof, the patient was reported to have moderate language delay. ${ }^{27}$

In addition to the case reported by Kriek et al., ${ }^{27}$ our example of two maternally inherited microduplications indicates that in some cases, parents can transmit the microduplication to their children. Although detailed clinical information is not available for the transmitting parents, there appears to be the possibility of intrafamilial phenotypic variability. The apparently high frequency of parental transmission is striking in comparison to the rarity of published cases of parental transmission of the WBS deletion. ${ }^{46,47}$ The frequency of familial transmission is also high in patients with $22 \mathrm{q} 11.2$ microduplication, ${ }^{48}$ possibly due to the milder or more variable phenotype in reciprocal duplication syndromes compared with the classical deletion syndromes. These findings suggest that the prevalence of $\operatorname{dup}(7)(\mathrm{q} 11.23)$ could be higher than previously expected. Both maternal and paternal transmisssion of the duplicated region from unaffected parents has now been shown, but whether there is a difference in phenotype between maternally and paternally inherited microduplications remains to be formally examined.

Our identification of seven probands and two parents who harbor microduplication of chromosome 7q11.23 emphasizes the value of new diagnostic modalities such as array-CGH that provide high-resolution genomic analysis and reveal specific etiological molecular abnormalities. This approach allows simultaneous analysis of copy number in a large number of genomic regions known to be involved in recurrent deletions or duplications, including telomere abnormalities, interstitial deletions and reciprocal duplications in well-characterized genomic regions, and copy number variation where the phenotype may not be clinically recognizable or remains to be fully delineated. Although FISH can reliably detect genomic deletions, the difficulty of obtaining accurate interphase FISH interpretation for duplications ${ }^{31}$ and the discrepancy between CMA and interphase FISH in one case documented here renders interphase FISH highly problematic in making the diagnosis of dup(7)(q11.23).

\section{Phenotype of patients with dup(7)(q11.23) syndrome}

Can we define a characteristic phenotype in patients with $\operatorname{dup}(7)(\mathrm{q} 11.23)$ syndrome? The most striking feature of the patient reported by Somerville et al. ${ }^{26}$ was the severe language delay, and the patients reported by Kriek et al. ${ }^{27}$ and Torniero et al. ${ }^{28}$ were also noted to have moderate to severe language delay. The seven cases reported here provide additional information regarding the phenotypic spectrum seen in patients with the recombination reciprocal of the WBS microdeletion and extend the features to include behavioral symptoms overlapping with children diagnosed with ASDs. 


\section{Clinical features}

Although each of the children reported here is described as having minor dysmorphic features, the overall appearance was not particularly striking or specific (Fig. 2 and Table 1). Based on the previous case reports ${ }^{26-28}$ and our current data, individuals with microduplication of chromosome 7q11.23 demonstrate a variety of dysmorphic features, including a prominent forehead, high nasal bridge and/or deep-set eyes, long nasal tip and/or columella, thick helices of the ears, and short philtrum. It still may be premature to attempt to define a characteristic, clinically recognizable facial phenotype without evaluating larger numbers of patients, but an overall gestalt could include abnormalities of the forehead, nasal area, philtrum, lip, ears, and cranial contour that may be somewhat reminiscent of Floating-Harbor syndrome (MIM 136140), in some, particularly older individuals (Carolyn Bay and Bryan Hall, personal communication). Nevertheless, it is clear that the overall facial dysmorphology in patients with $\operatorname{dup}(7)$ (q11.23) syndrome is not as distinctive as the well-characterized facies associated with WBS.

Whether microduplication of the WBS region could lead to an increased incidence of birth defects (compared with the SVAS frequently seen in patients with WBS) or other physical abnormalities such as growth retardation or brain malformations also remains to be determined. All the patients described herein had growth percentiles within the normal range at birth and at the time of examination, in contrast to the growth retardation reported in one previous case report. ${ }^{26}$ The presence of cleft lip and palate in Patient 1 and a submucous cleft in Patient 7 raises the possibility of an increased incidence of clefting in this syndrome (possibly compounding the speech delay) and will require further evaluation. Several patients had unique clinical features such as severe vesicoureteral reflux in Patient 2, pes planus in Patient 3, neutropenia and astigmatism in Patient 5, and gastroesophageal reflux in Patient 7. Other features such as recurrent otitis media, hypotonia, and constipation were also present. No craniosynostosis was noted in our patients, in contrast to the patient reported by Kriek et al.,27 indicating that this feature is likely an uncommon aspect of $\operatorname{dup}(7)(q 11.23)$ syndrome. The presence of a seizure disorder in Patients 1 and 7 and the patient reported by Torniero et al. ${ }^{28}$ raises the possibility that epilepsy could be a feature of $\operatorname{dup}(7)(q 11.23)$ syndrome, but again this will require additional study to confirm or exclude. Brain MRI scans were obtained in Patients 1, 4, 5, and 6 before diagnosis, and although no structural abnormalities were identified, there were nonspecific changes including mild reduction in brain volume and white matter changes, the significance of which is unclear. These findings are in contrast to the report of Torniero et al.28 describing unilateral cortical dysplasia of the left temporal lobe in a patient with $\operatorname{dup}(7)(\mathrm{q} 11.23)$ and suggest that significant structural abnormalities visible at the level of MRI are not likely to be a general feature of patients with this syndrome. No cardiovascular malformations were present in our cohort of patients, although only one patient was formally evaluated with an echocardiogram.

\section{Cognitive features}

Each child in this study was ascertained due to developmental delay, with speech delay being a predominant feature. Patients 1 and 4 exhibited moderate to severe expressive language impairment in that they showed minimal ability to use words verbally and their speech was difficult to understand. The speech difficulty seen in Patients 1 and 7 could be compounded by the presence of clefting and the surgeries required for correction. Patient 3 also exhibited speech delay but improved dramatically between $4 \frac{1}{2}$ and 5 years of age, coincident with fluoxetine treatment for severe anxiety. Patients 2, 5, and 7 were older at the time of evaluation and had acquired the use of verbal words and phrases. Patient 6 displayed severe speech delay (using only single words at 6 years of age) but also had significant global developmental delay. Patient $5^{\mathrm{m}}$ entered college and Patient $6^{\mathrm{m}}$ completed high school, suggesting either variable penetrance of the speech delay phenotype among family members or the potential to overcome early childhood speech impairment. Although we acknowledge that the lack of formal testing for several patients in this cohort is a weakness of the current study, delineation of the overall cognitive spectrum seen in patients with $\operatorname{dup}(7)(\mathrm{q} 11.23)$ is an important matter that will need to be addressed in future studies of a larger cohort of patients.

Interestingly, the three younger children have developed nonverbal gestures as a means of communicating and compensating for their significant speech delays, although they differed in the degree to which they were fluent in using these signs and gestures. For example, Patient 3 was quite fluent in her use of signs and gestures and this is reflected in her language scores on formal testing. It is possible that Patients 1 and 4 (who are both younger) have not received the intensity of interventions for the same amount of time as have been received by Patient 3 , and this could account for some of the apparent disparity between them. Interestingly, these features share some similarity to developmental verbal dyspraxia (MIM 602081), a disorder of speech production and language processing that has been associated with mutations in the FOXP2 gene. ${ }^{49}$

In our patients for whom standardized cognitive testing was performed, relative strength in nonverbal cognitive skills was observed, which seems to contrast with the patient reported by Somerville et al. ${ }^{26}$ whose nonverbal and spatial scores were in the range of mild deficiency (although this was interpreted as being consistent with other family members). The significant language impairment with sparing of visuospatial cognitive skills in patients with $\operatorname{dup}(7)(\mathrm{q} 11.23)$ syndrome is in direct contrast to the typical cognitive profile of patients with WBS, in whom verbal skills are a relative strength and visuospatial skills are severely impaired. ${ }^{13}$

\section{Behavioral features}

The behavioral symptoms observed in our patients have not previously been detailed in other patients with $\operatorname{dup}(7)(\mathrm{q} 11.23)$ 
syndrome, and formal behavioral testing has not been reported. ${ }^{26-28}$ While this article was in preparation, Kirchhoff and colleagues ${ }^{50}$ described a single patient with microduplication of chromosome 7q11.23 in a series of 258 mentally retarded and dysmorphic patients with normal conventional karyotypes. Although limited clinical information was provided, this 23-year-old man was suspected to have Asperger syndrome. ${ }^{50}$

Our probands exhibit behavioral features often observed in children diagnosed with ASDs, but the specific features and severity of the symptoms varied between patients. Characteristic findings included using another person's hand as a "tool" for communication, difficulties with eye gaze, limited facial expressions, repetitive behaviors, repetitive play, repetitive speech, sensory integration problems, and difficulty with social interactions including anxiety or withdrawal. The male patients have additional problems with hyperactivity, self-injury, and aggression. It is worth noting that aberrant behaviors can also be observed in children with mental retardation ${ }^{51-53}$ and are certainly not specific to the cases we have described here. Nevertheless, the behavioral checklist is normalized for use in patients with mental retardation, and therefore any elevations are above those seen in patients with mental retardation. Furthermore, these features raise the possibility that autism spectrum behaviors could be part of the phenotype of $\operatorname{dup}(7)(\mathrm{q} 11.23)$ syndrome and are borne out by elevations on ADOS-G testing in several of the individuals. Our results suggest that patients with $\operatorname{dup}(7)(\mathrm{q} 11.23)$ syndrome may first be ascertained through an evaluation for an ASD, even if they do not ultimately meet formal diagnostic criteria. Moreover, this feature may be somewhat age dependent and mitigated on acquisition of language skills (as evidenced by the improvement over time in Patients 2 and 3, who both fell below the ASD cutoff at the time of ADOS examination), although this possibility remains to be formally evaluated. Interestingly, many individuals with WBS also exhibit autism spectrum behavioral abnormalities including pragmatic language impairments, poor social relationships, and restricted interests. ${ }^{54-56}$ Patients with atypical 7q11.23 microdeletions may also exhibit autismspectrum behaviors. ${ }^{57}$

Psychiatric disorders as a whole are prevalent in children and adolescents with WBS, including anxiety and phobias. ${ }^{58}$ Interestingly, anxiety symptoms were a significant issue for Patients 1, 3, 4, and 7. ADHD is common $(>60 \%)$ in children and adolescents with $\mathrm{WBS}^{58}$ and was also present in the patient described by Somerville et al. ${ }^{26}$ Similarly, Patients 1 and 2 were diagnosed with ADHD, although they, like the patient described by Somerville et al., also had siblings with ADHD. Patient 6 was suspected to have ADHD but has not yet undergone formal evaluation. Therefore, it is unclear whether the attention deficit and hyperactivity seen in our patients is related to altered gene dose in the WBS region or to other familial factors. However, it is certainly possible that comorbid ADHD or anxiety could alter the behavioral phenotype in patients with $\operatorname{dup}(7)(q 11.23)$ syndrome.

\section{CONCLUSIONS}

The overall cognitive and behavioral phenotype seen thus far in patients with microduplication of chromosome 7q11.23 is very interesting with respect to patients with WBS. The expressive language delay with sparing of visuospatial cognition in patients with duplication of the WBS region is in direct contrast to the well-characterized cognitive profile seen in typical WBS patients, ${ }^{13}$ whereas the relative behavioral withdrawal is the converse of the typically outgoing personality profile observed in patients with WBS. ${ }^{13,59}$ Similar to patients with WBS in whom psychiatric problems are a feature, ${ }^{58}$ patients with microduplication of the WBS region also appear to be at risk of ADHD and/or anxiety. These findings further support the speculation that in addition to harboring genes involved in cognition and language, this region may also contain genes involved in development of social behavior. The molecular and neuroanatomical substrates of these features are of great interest, ${ }^{60}$ and it is possible that genes within this region are expressed in brain structures important for language, visuospatial cognition, and social behavior in such a way that changes in gene dose have different classes of effects. For such dose-sensitive genes, alleles with varying degrees of activity on the normal chromosome (in the case of deletion) or on either chromosome (in the case of duplication) could modify the effect of the genomic rearrangement. One class of dosagesensitive genes could affect pathways in reciprocal fashion, resulting in converse phenotype in deletion and duplication patients. A different class of dosage-sensitive genes could disrupt the same pathway, resulting in features shared by the two syndromes, such as anxiety and (possibly) ADHD. Furthermore, contributions of other genes outside the deleted or duplicated region could play an important role in modifying the phenotype, either through position effect on expression of nearby genes $^{22}$ or through molecular pathways that are shared with genes in the rearranged interval.

In conclusion, array-CGH has proven to be a powerful means of identifying individuals with genomic imbalances, and we propose that $\operatorname{dup}(7)(\mathrm{q} 11.23)$ syndrome may be identified much more frequently as greater numbers of patients with expressive language delay and behavioral abnormalities are screened for genomic rearrangements. Our data suggest that $\operatorname{dup}(7)(\mathrm{q} 11.23)$ syndrome, the recombination reciprocal of the WBS microdeletion syndrome, results in a phenotype that includes significant speech delay and may also commonly involve autism-spectrum behavioral abnormalities. Indeed, it is important for clinicians to recognize that individuals with $\operatorname{dup}(7)(\mathrm{q} 11.23)$ syndrome may first present for an autism evaluation prompted by language delay and behavioral concerns, even if they are ultimately found not to meet the gold standard criteria for autism. Additionally, we propose that dup(7)(q11.23) syndrome does not appear to have strongly reproducible or pathognomonic physical features. However, further definition of the range of speech and language impairment, behavioral abnormalities, and associated clinical features will require de- 
tailed study and longitudinal monitoring of larger numbers of patients.

\section{AKNOWLEDGEMENTS}

J.S.B. was supported in part by departmental training grant NIH T32 GM07526-29. The financial support of TelethonItaly (fellowship GFP04008) to N.B.-P. is gratefully acknowledged. The authors thank Lance Cooper and all the members of the FISH and CMA labs at the Kleberg Cytogenetics Laboratory for their assistance. The authors deeply appreciate the cooperation of the patients and their families.

\section{References}

1. Lupski JR. Genomic disorders: structural features of the genome can lead to DNA rearrangements and human disease traits. Trends Genet 1998;14:417-422.

2. Greenberg F. Williams syndrome professional symposium. Am J Med Genet 1990;6: 85-88.

3. Osborne LR. Williams-Beuren syndrome: unraveling the mysteries of a microdeletion disorder. Mol Genet Metab 1999;67:1-10.

4. Stromme P, Bjornstad PG, Ramstad K. Prevalence estimation of Williams syndrome. J Child Neurol 2002;17:269-271.

5. Stankiewicz P, Lupski JR. Genome architecture, rearrangements and genomic disorders. Trends Genet 2002;18:74-82.

6. Urban Z, Helms C, Fekete G, Csiszar K, et al. 7q11.23 deletions in Williams syndrome arise as a consequence of unequal meiotic crossover. Am J Hum Genet 1996; 59:958-962.

7. Bayes M, Magano LF, Rivera N, Flores R, et al. Mutational mechanisms of WilliamsBeuren syndrome deletions. Am J Hum Genet 2003;73:131-151.

8. Korenberg JR, Chen XN, Hirota H, Lai Z, et al. VI. Genome structure and cognitive map of Williams syndrome. J Cogn Neurosci 2000;12(SupplementSuppl 1):89-107.

9. Hillier LW, Graves TA, Fulton RS, Fulton LA, et al. The DNA sequence of human chromosome 7. Nature 2003;424:157-164.

10. Osborne LR, Li M, Pober B, Chitayat D, et al. A 1.5 million-base pair inversion polymorphism in families with Williams-Beuren syndrome. Nat Genet 2001;29: 321-325.

11. Morris CA, Demsey SA, Leonard CO, Dilts C, et al. Natural history of Williams syndrome: physical characteristics. J Pediatr 1988;113:318-326.

12. Francke U. Williams-Beuren syndrome: genes and mechanisms. Hum Mol Genet 1999;8:1947-1954.

13. Mervis CB, Klein-Tasman BP. Williams syndrome: cognition, personality, and adaptive behavior. Ment Retard Dev Disabil Res Rev 2000;6:148-158.

14. Peoples R, Franke Y, Wang YK, Perez-Jurado L, et al. A physical map, including a $\mathrm{BAC} / \mathrm{PAC}$ clone contig, of the Williams-Beuren syndrome-deletion region at 7q11.23. Am J Hum Genet 2000;66:47-68.

15. DeSilva U, Elnitski L, Idol JR, Doyle JL, et al. Generation and comparative analysis of approximately $3.3 \mathrm{Mb}$ of mouse genomic sequence orthologous to the region of human chromosome 7q11.23 implicated in Williams syndrome. Genome Res 2002; $12: 3-15$

16. Merla G, Ucla C, Guipponi M, Reymond A. Identification of additional transcripts in the Williams-Beuren syndrome critical region. Hum Genet 2002;110:429-438.

17. Ewart AK, Morris CA, Atkinson D, Jin W, et al. Hemizygosity at the elastin locus in a developmental disorder, Williams syndrome. Nat Genet 1993;5:11-15.

18. Hoogenraad CC, Eussen BHJ, Langeveld A, van Haperen R, et al. The murine CYLN2 gene: genomic organization, chromosome localization, and comparison to the human gene that is located within the $7 \mathrm{q} 11.23$ Williams syndrome critical region. Genomics 1998;53:348-358.

19. Meng Y, Zhang Y, Tregoubov V, Janus C, et al. Abnormal spine morphology and enhanced LTP in LIMK-1 knockout mice. Neuron 2002;35:121-133.

20. Tassabehji M. Williams-Beuren Syndrome: a challenge for genotype-phenotype correlations. Hum Mol Genet 2003;15:229-237.

21. Tassabehji M, Hammond P, Karmiloff-Smith A, Thompson P, et al. GTF2IRD1 in craniofacial development of humans and mice. Science 2005;310:1184-1187.

22. Merla G, Howald C, Henrichsen CN, Lyle R, et al. Submicroscopic deletion in patients with Williams-Beuren syndrome influences expression levels of the nonhemizygous flanking genes. Am J Hum Genet 2006;79:332-341.

23. Potocki L, Chen K-S, Park S-S, Osterholm DE, et al. Molecular mechanism for duplication 17p11.2 - the homologous reciprocal of the Smith-Magenis microdeletion. Nat Genet 2000;24:84-87.
24. Bi W, Park SS, Shaw CJ, Withers MA, et al. Reciprocal crossovers and a positional preference for strand exchange in recombination events resulting in deletion or duplication of chromosome 17p11.2. Am J Hum Genet 2003;73:1302-1315.

25. Ensenauer RE, Adeyinka A, Flynn HC, Michels VV, et al. Microduplication 22q11.2, an emerging syndrome: clinical, cytogenetic, and molecular analysis of thirteen patients. Am J Hum Genet 2003;73:1027-1040.

26. Somerville MJ, Mervis CB, Young EJ, Seo E-J, et al. Severe expressive-language delay related to duplication of the Williams-Beuren Locus. NEngl J Med 2005;353:1694-1701.

27. Kriek M, White SJ, Szuhai K, Knijnenburg J, et al. Copy number variation in regions flanked (or unflanked) by duplicons among patients with developmental delay and/or congenital malformations: detection of reciprocal and partial WilliamsBeuren duplications. Eur J Hum Genet 2006;14:180-189.

28. Torniero C, Bernardina BD, Novara F, Vetro A, et al. Cortical dysplasia of the left temporal lobe might explain severe expressive-language delay in patients with duplication of the Williams-Beuren locus. Eur J Hum Genet 2006;15:62-67.

29. Cheung SW, Shaw CA, Yu W, Li J, et al. Development and validation of a CGH microarray for clinical cytogenetic diagnosis. Genet Med 2005;7:422-432.

30. Lupski JR, Stankiewicz P, editors. Genomic disorders-the genomic basis of disease. Totowa, NJ: Humana Press, 2005.

31. Shaffer LG, Kennedy GM, Spikes AS, Lupski JR. Diagnosis of CMT1A duplications and HNPP deletions by interphase FISH: implications for testing in the cytogenetics laboratory. Am J Med Genet 1997;69:325-331.

32. Peiffer DA, Le JM, Steemers FJ, Chang W, et al. High-resolution genomic profiling of chromosomal aberrations using Infinium whole-genome genotyping. Genome Res 2006;16:1136-1148.

33. Bayley N. Bayley Scales of Infant Development, 2nd ed. San Antonio, TX: Psychological Corporation, 2006.

34. Sparrow SS, Cicchetti DV, Bala DA. Vineland Adaptive Behavior Scales, interview edition: survey form manual. Circle Pines, MN: American Guidance Service, 2005.

35. Wechsler D. Wechsler Preschool and Primary Scale of Intelligence, 3rd ed. San Antonio: Psychological Corporation, 2002.

36. Beery KE, Buktenica NA, Beery NA. Beery Developmental Test of Visual Motor Integration, 5th ed. Parsipppany, NJ: Modern Curriculum Press, 2004.

37. Wechsler D. Wechsler Intelligence Scale for Children, 3rd ed. San Antonio: Psychological Corporation, 1991.

38. Kaufman AS, Kaufman NL. Kaufman Assessment Battery for Children. Minneapolis: AGS Assessment, 1983.

39. Aman MG, Singh NN. Aberrant Behavior Checklist. East Aurora, IL: Slosson Educational Publications, 1994.

40. Lord C, Rutter M, DiLavore PC, Risi S. Autism Diagnostic Observation Schedule. Los Angeles: Western Psychological Services, 2002.

41. Kent WJ, Sugnet CW, Furey TS, Roskin KM, et al. The Human Genome Browser at UCSC. Genome Res 2002;12:996-1006.

42. Bailey JA, Yavor AM, Massa HF, Trask BJ, et al. Segmental duplications: organization and impact within the current human genome project assembly. Genome Res 2001;11:1005-1017.

43. Bailey JA, Gu Z, Clark RA, Reinert K, et al. Recent segmental duplications in the human genome. Science 2002;297:1003-1007.

44. Shaw CJ, Lupski JR. Implications of human genome architecture for rearrangementbased disorders: the genomic basis of disease. Hum Mol Genet 2004;13:R57-64.

45. Stankiewicz P, Lupski JR. Genomic disorders: molecular mechanisms for rearrangements and conveyed phenotypes. PLoS Genet 2005;1:e49.

46. Morris CA, Thomas IT, Greenberg F. Williams syndrome: autosomal dominant inheritance. Am J Med Genet 1993;47:478-481.

47. Pankau R, Siebert R, Kautza M, Schneppenheim R, et al. Familial Williams-Beuren syndrome showing varying clinical expression. Am J Med Genet 2001;98:324-329.

48. Portnoi M-F, Lebas F, Gruchy N, Ardalan A, et al. 22q11.2 duplication syndrome: two new familial cases with some overlapping features with DiGeorge/velocardiofacial syndromes. Am J Med Genet 2005;137A:47-51.

49. Lai CSL, Fisher SE, Hurst JA, Vargha-Khadem F, et al. A forkhead-domain gene is mutated in a severe speech and language disorder. Nature 2005;413:519-523.

50. Kirchhoff M, Bisgaard A-M, Bryndorf T, Gerdes T. MLPA analysis for a panel of syndromes with mental retardation reveals imbalances in $5.8 \%$ of patients with mental retardation and dysmorphic features, including duplications of the Sotos syndrome and Williams-Beuren syndrome regions. Eur J Med Genet 2007;50:33-42.

51. Campbell M, Malone RP. Mental retardation and psychiatric disorders. Hosp Community Psychiatry 1991;42:374-379.

52. Lovell RW, Reiss AL. Dual diagnoses: psychiatric disorders in developmental disabilities. Pediatr Clin North Am 1993;40:579-592.

53. Moss S, Emerson E, Bouras N, Holland A. Mental disorders and problematic behaviours in people with intellectual disability: future directions for research. J Intellect Disabil Res 1997;41:440-447.

54. Reiss AL, Feinstein C, Rosenbaum KN, Borengasser-Caruso MA, et al. Autism associated with Williams syndrome. J Pediatr 1985;106:247-249. 
55. Gillberg C, Rasmussen P. Brief report: four case histories and a literature review of Williams syndrome and autistic behavior. J Autism Dev Disord 1994;24:381-393.

56. Laws G, Bishop D. Pragmatic language impairment and social deficits in Williams syndrome: a comparison with Down's syndrome and specific language impairment. Int J Lang Commun Disord 2004;39:45-64.

57. Edelmann L, Prosnitz A, Pardo S, Bhatt J, et al. An atypical deletion of the WilliamsBeuren Syndrome interval implicates genes associated with defective visuospatial processing and autism. J Med Genet 2006;44:136-143.
58. Leyfer OT, Woodruff-Borden J, Klein-Tasman BP, Fricke JS, et al. Prevalence of psychiatric disorders in 4 to 16-year-olds with Williams syndrome. Am J Med Genet B Neuropsychiatr Genet 2006;141:615-622.

59. Klein-Tasman BP, Mervis CB. Distinctive personality characteristics of 8-, 9-, and 10-year-olds with Williams syndrome. Dev Neuropsychol 2003;23:269-290.

60. Meyer-Lindenberg A, Mervis CB, Berman KF. Neural mechanisms in Williams syndrome: a unique window to genetic influences on cognition and behaviour. Nat Rev Neurosci 2006;7:380-393. 